\title{
European Thyroid Association Survey on Use of Minimally Invasive Techniques for Thyroid Nodules
}

\author{
Laszlo Hegedüs $^{\text {a }}$ Andrea Frasoldati $^{b}$ Roberto Negro ${ }^{c}$ Enrico Papini ${ }^{d}$ \\ ${ }^{a}$ Department of Endocrinology and Metabolism, Odense University Hospital, Odense, Denmark; ${ }^{b}$ Division of \\ Endocrinology, Arcispedale S. Maria Nuova, Reggio Emilia, Italy; 'Division of Endocrinology, "V. Fazzi" Hospital, \\ Lecce, Italy; ${ }^{\mathrm{d}}$ Division of Endocrinology, Regina Apostolorum Hospital, Albano Laziale, Italy
}

\section{Keywords}

Thyroid nodules · Thyroid cysts - Thyroid cancer .

Questionnaire - Laser ablation - Radiofrequency ablation ·

Ethanol ablation - Thermal ablation - European thyroid association

\section{Abstract \\ Objective: Image-guided interventional ultrasound (US) techniques represent diagnostic and therapeutic tools for non-surgical management of thyroid nodular disease. We sought to investigate the attitude of European Thyroid Asso- ciation (ETA) members towards the use of minimally invasive techniques (MIT) in diagnosis/therapy of symptomatic nodu- lar goitre. Methods: ETA members were invited to participate in an online survey investigating the use of MIT in benign and malignant thyroid nodular disease. Of 865 invited members, $221(25.5 \%)$ completed the survey. The respondents were from 40 countries; 139 (74.7\%) were from European coun- tries. Results: Respondents personally performed thyroid US (91.6\%), Fine needle aspiration (FNA; 75.3\%), ethanol abla- tion (EA; 22.1\%), core needle biopsy (CNB; 11\%) and thermal treatments (4.8\%). When skills and/or technology were un- available, only $13.4 \%$ referred patients "often" or "always" to other centres with specific expertise in this field. Surgery was}

karger@karger.com www.karger.com/etj

2020 European Thyroid Association Published by S. Karger AG, Basel
Karger" the preferred first option in patients with recurrent cysts, 4.0 $\mathrm{cm}$ benign nodules, local (radioiodine-avid or non-avid) lymph node metastases, or papillary cancers $<1.0 \mathrm{~cm}$. For autonomously functioning nodules radioactive iodine treatment was the preferred choice, followed by surgery. Thermal ablation (TA) was the preferred option only for a $4 \mathrm{~cm}$ benign nodule in old patients with comorbidities. Conclusions: US, US-guided FNA and surgery were available to nearly all respondents, while MIT was not. CNB and EA were employed only by about $1 / 3$ of the respondents and TA procedures were available and personally performed only by a minority. For most thyroid lesions, surgery was the preferred option versus thermal therapies. The ETA needs to develop guidelines and establish teaching to overcome geographic inequality and promote the use of MIT as a valid therapy option in appropriate cases.

(c) 2020 European Thyroid Association Published by S. Karger AG, Basel

\section{Introduction}

In the thyroid field, image-guided interventional ultrasound (US) techniques have globally been recognised and increasingly employed over the last 4 decades. Their 
Table 1. Characteristics of the 221 respondents

\begin{tabular}{|c|c|}
\hline \multicolumn{2}{|l|}{ Gender, $n(\%)^{\dagger}$} \\
\hline Male & $96(49.7)$ \\
\hline Female & $97(50.3)$ \\
\hline \multicolumn{2}{|l|}{ Age, years, $n(\%)^{\dagger}$} \\
\hline $20-30$ & $7(3.6)$ \\
\hline $31-40$ & $40(20.7)$ \\
\hline $41-50$ & $36(18.7)$ \\
\hline $51-60$ & $60(31.1)$ \\
\hline $61-70$ & $37(19.2)$ \\
\hline$>70$ & $13(6.7)$ \\
\hline \multicolumn{2}{|l|}{ Years of practicing medicine, $n(\%)^{\#}$} \\
\hline$<10$ & $26(13.7)$ \\
\hline $10-20$ & $47(24.7)$ \\
\hline $20-30$ & $37(19.5)$ \\
\hline $30-40$ & $55(28.9)$ \\
\hline$>40$ & $25(13.2)$ \\
\hline \multicolumn{2}{|l|}{ Specialty, $n(\%)^{*}$} \\
\hline Endocrinology & $158(83.2)$ \\
\hline Internal medicine & $35(18.4)$ \\
\hline Nuclear medicine & $20(10.5)$ \\
\hline Surgery & $11(5.8)$ \\
\hline Radiology & $5(2.6)$ \\
\hline Others & $12(6.3)$ \\
\hline \multicolumn{2}{|l|}{ Member, $n(\%)^{*}$} \\
\hline ETA & $190(98.4)$ \\
\hline ATA & $34(17.6)$ \\
\hline LATS & $4(2.1)$ \\
\hline AOTA & 0 \\
\hline National Endocrine Society & $115(59.6)$ \\
\hline None of the above & $1(0.5)$ \\
\hline \multicolumn{2}{|l|}{ Where do you practice?, $n(\%)^{*}$} \\
\hline Academic/University Centre & $124(64.6)$ \\
\hline Regional Hospital & $40(20.8)$ \\
\hline Private clinic & $46(24)$ \\
\hline General practice & $8(4.2)$ \\
\hline Basic researcher & $3(1.6)$ \\
\hline \multicolumn{2}{|c|}{ 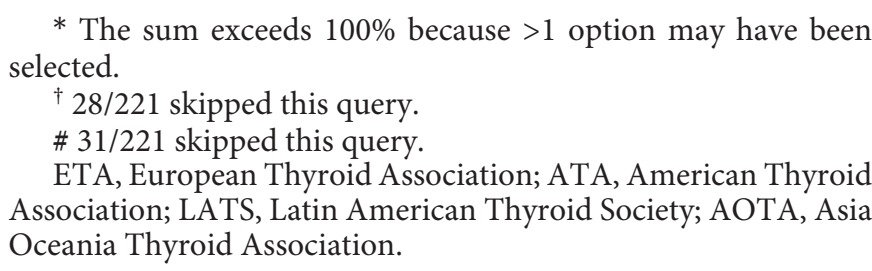 } \\
\hline
\end{tabular}

role, especially in the diagnosis and treatment of nodular thyroid disease, is well accepted [1-3]. Fine needle aspiration (FNA) and, to a lesser extent, core needle biopsy (CNB), are currently recognized as the primary diagnostic methods for evaluating thyroid lesions, cervical lymphnode metastases and local persistence of benign as well as malignant thyroid disease [2, 4-6]. Minimally invasive techniques (MIT), such as ethanol ablation (EA) and thermal ablation (TA) such as laser ablation (LA) or radiofrequency ablation (RFA), have been successfully used to treat thyroid cysts and benign nodules associated with symptoms of compression, and are currently routinely used in some European countries as well as in the Far East $[1,3,7]$.

Recently, TA of thyroid tissue, that is destruction by heating and subsequent coagulative necrosis and fibrosis, was proven effective for the local control of papillary thyroid microcarcinomas (PTMC) and metastatic lymph nodes in patients at surgical risk $[8,9]$. Furthermore, a few centres have used TA for palliative purposes in thyroid cancer, neither amenable to surgical resection nor radioiodine ablation (RAI), with promising results $[10,11]$. In addition to LA and RFA, other techniques, like high intensity focused US (HIFU) and microwave ablation (MWA), are being tested for ablation of benign and malignant thyroid nodules [12, 13].

Although there is a growing body of evidence to support the use of these procedures, we have very little information on their current dissemination into the clinical practice of European thyroidologists. Hence, we carried out a survey among European Thyroid Association (ETA) members aimed at investigating the attitude of ETA members towards the use of MIT in diagnosis/therapy of symptomatic nodular goitre. Imitating well-recognizable clinical situations, despite using virtual patients for illustration, our survey intended to cover MIT of some of the most common thyroid nodule phenotypes.

\section{Methods}

We utilized a web-based survey based on a questionnaire comprising 27 questions. A total of 865 ETA members were sent an initial e-mail between April 1st and 30th 2019, including an electronic link to the questionnaire, followed by 2 reminders with a 2 -week interval. Survey responses were collected and electronically stored by the survey service where they were accessible by password. The survey service automatically blocked repeat submissions from the same IP address. The entire survey is available (online suppl. Appendix 1; for all online suppl. material, see www. karger.com/doi/10.1159/000506513).

\section{Statistical Analyses}

Summary statistics were prepared for responses to each question. We considered valid for statistical evaluation only those questionnaires with complete demographic data from the respondents. Pearson's $\chi^{2}$ test or Fisher's exact test were used to compare frequencies (percentages) between categorical variables. A two-sided $p$ value of $<0.05$ was considered statistically significant. Data was analysed using IBM SPSS Statistics version 19 software (SPSS, Chicago, IL, USA). 


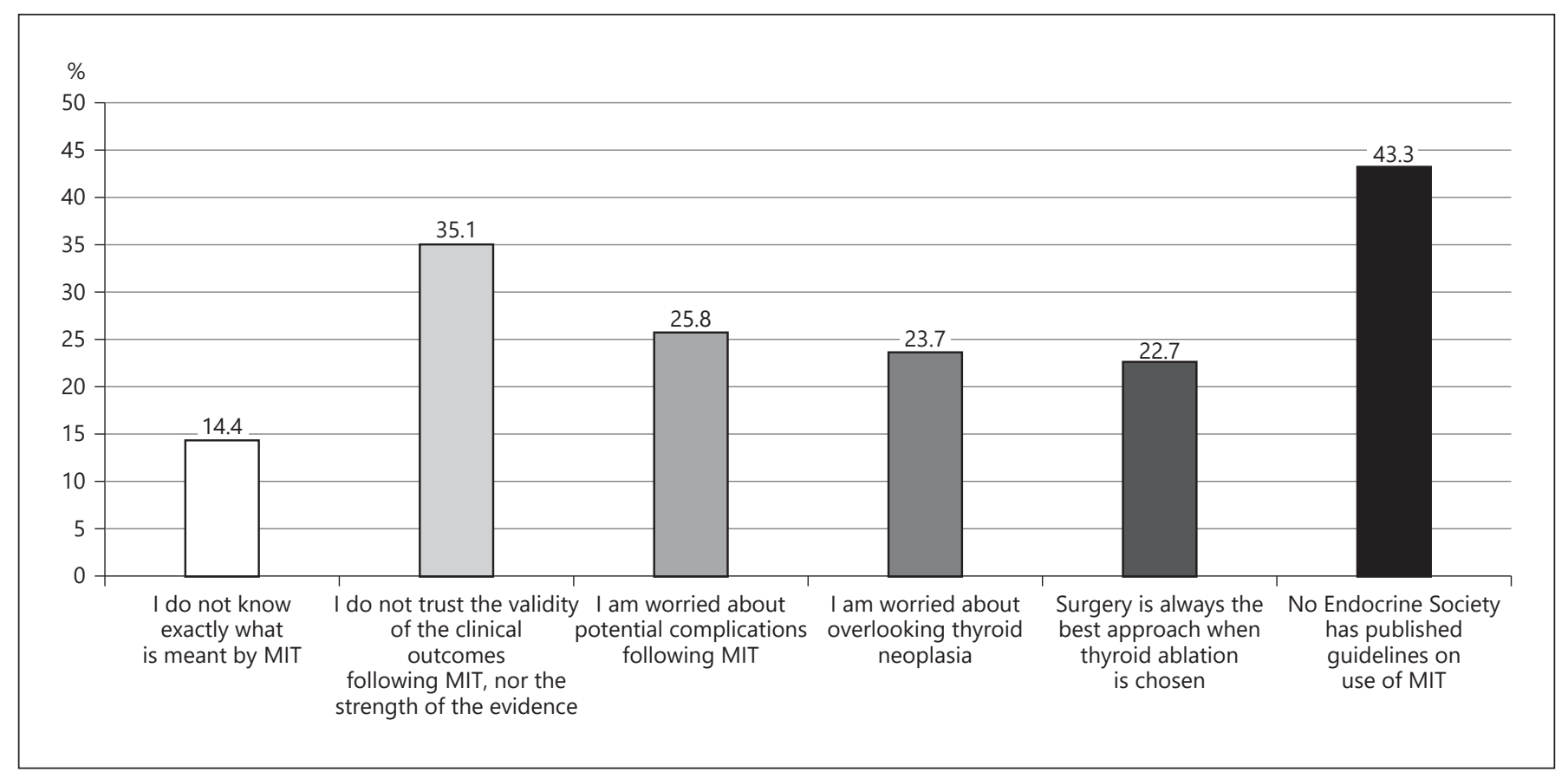

Fig. 1. Reasons given for physicians never, or rarely, referring patients to MIT (Question 14). The sum exceeds $100 \%$ because $>1$ option could be selected by the respondents. MIT, minimally invasive techniques.

\section{Results}

\section{Sample Characteristics}

510 of 865 (59\%) ETA members opened the survey, $261(30.2 \%)$ started the survey and 221 (25.5\%) scrolled entirely the questionnaire; the mean number of respondents for the 26 questions was $178 \pm 22$. Characteristics of respondents are presented in Table 1 (Questions 1-6).

Of the respondents, $155(80.3 \%)$ treated thyroid patients on a daily, and $30(15.5 \%)$ on a weekly basis. 127 $(66.1 \%)$ treated $>100$ patients/year with nodular thyroid disease, 33 (17.2\%) treated 50-100 patients/year, and 24 (12.5\%) 10-50 patients/year (Questions 7, 8). The respondents were from 40 countries; 139 (74.7\%) were from European countries, with the majority of them being from Italy $(31 ; 16.5 \%)$, Denmark $(13 ; 6.9 \%)$ or France (10; 5.3\%; online suppl. Appendix 2; Question 9).

\section{Diagnostic and Therapeutic Modalities}

US, FNA and surgery of the thyroid were virtually available in every hospital/clinic of the respondents (99.5, 97.4, $82.5 \%$ respectively), while minimally invasive diagnostic and therapeutic procedures like $\mathrm{CNB}$ and EA were available for 33.9 and $36.5 \%$, respectively, and thermal treatments to even fewer (RFA: 23.3\%; LA: 12.7\%; HIFU:
13.8\%; MWA: 2.6\%; Question 10). Thus, the combination of US, FNA and surgery was, in European centres usually dealing with thyroid diseases, significantly more available and used than the minimally invasive diagnostic and therapeutic tools $(p<0.01)$.

In all, $91.6 \%$ of the respondents personally performed thyroid US, $75.3 \%$ performed FNA, while percentages were much lower concerning the interventional treatment options (EA: 22.1\%; thermal treatments: 4.8\%; Question 11). Performance of US and FNA was thus much more commonly carried out than the other interventional diagnostic and therapeutic modalities $(p<$ $0.01)$. In the hospitals of the respondents, but not by them personally, $80 \%$ were able to offer US, FNA and thyroid surgery. However, this figure was reduced to between 10 and $33 \%$ concerning ability to offer MIT (US, FNA and thyroid surgery versus MIT; $p<0.01$; Question 12 ). When skills and/or instruments in the institutions of the respondents were not available for performing MIT, 13.4\% referred their patients "often" or "always" to other centres with specific expertise in this field, whereas $86.6 \%$ referred "sometimes," "rarely" or "never" to institutions that routinely perform these procedures (sometimes/ rarely/never versus often/always; $p<0.01$; Question 13). The reasons for physicians being reluctant to refer pa- 
Fig. 2. a Choice of therapy for a 25-year old female with a $4.0 \mathrm{~cm}$ spongiform nodule (EU-TIRADS 2 with a benign FNA) causing symptoms of compression (Question 19). b Choice of therapy for a 75-year old male patient with a similar thyroid nodule, but now suffering from diabetes, cardiovascular disease and renal failure (Question 20). HIFU, high intensity focused US.

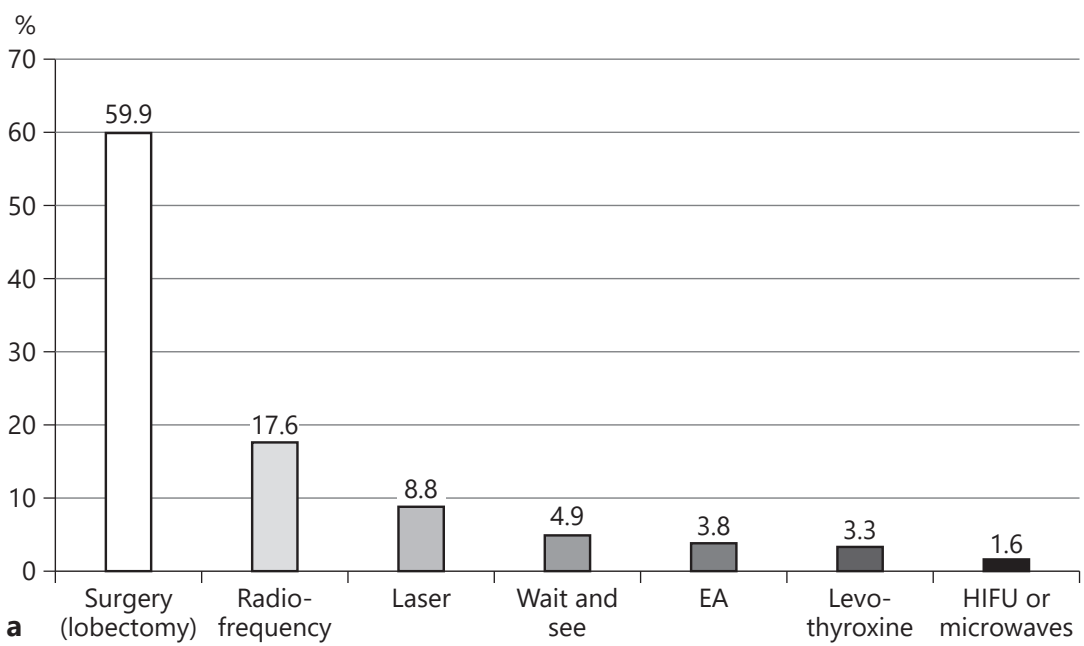

$\%$

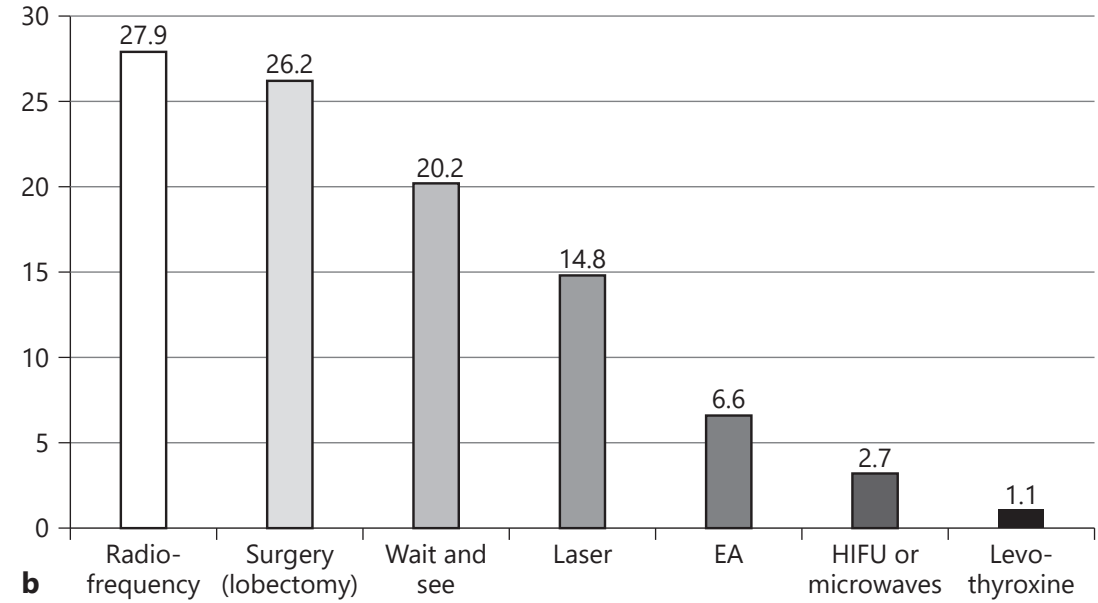

tients to minimally invasive treatments included the absence of dedicated guidelines, uncertainty about clinical outcomes, concern of potential complications and fear of overlooking a thyroid cancer. Notably, $14.4 \%$ stated that they did not know exactly what is meant by minimally invasive treatments, and $22.7 \%$ believed in the superiority of surgery (Fig. 1; Question 14).

Subsequent questions aimed at investigating the clinical management of patients, that is, when and how MIT was offered.

\section{Core Needle Biopsy}

CNB was used by $52.0 \%$ for thyroid nodules with repeated non diagnostic FNA cytology and by $53.7 \%$ when there was suspicion of anaplastic carcinoma, metastasis or lymphoma. In contrast, it was used by $15.4 \%$ for nod- ules initially diagnosed as atypia of undetermined significance or follicular lesion of undetermined significance (Bethesda Class III) and by $13.0 \%$ for nodules initially diagnosed as follicular neoplasm or suspicion for follicular neoplasm (Bethesda class IV) [14]. The aggregate exceeds $100 \%$ because $>1$ option could be selected by the respondents (inadequate FNA cytology, suspected anaplastic carcinoma, metastasis or lymphoma vs. Bethesda Class III-IV; $p<0.01$; Question 15).

\section{Cystic Lesion}

For a 25-year-old woman with a $4.0 \mathrm{~cm}$ thyroid cyst, $71.4 \%$ would aspirate the cystic fluid with associated cytological examination (aspiration vs. other options; $p<$ 0.01 ; Question 16). If the cyst recurred, $41.1 \%$ would offer EA, while $35.7 \%$ would refer the patient to surgery (EA 
Fig. 3. a Choice of therapy for a 65-year-old female patient with a $4.0 \mathrm{~cm}$ AFTN causing symptoms of compression and subclinical hyperthyroidism (Question 22). b Choice of therapy for a 20-year-old female patient with a $2.5 \mathrm{~cm}$ autonomously functioning nodule causing subclinical hyperthyroidism but no symptoms of compression (Question 23). MIT, minimally invasive techniques; RAI, radioiodine ablation.

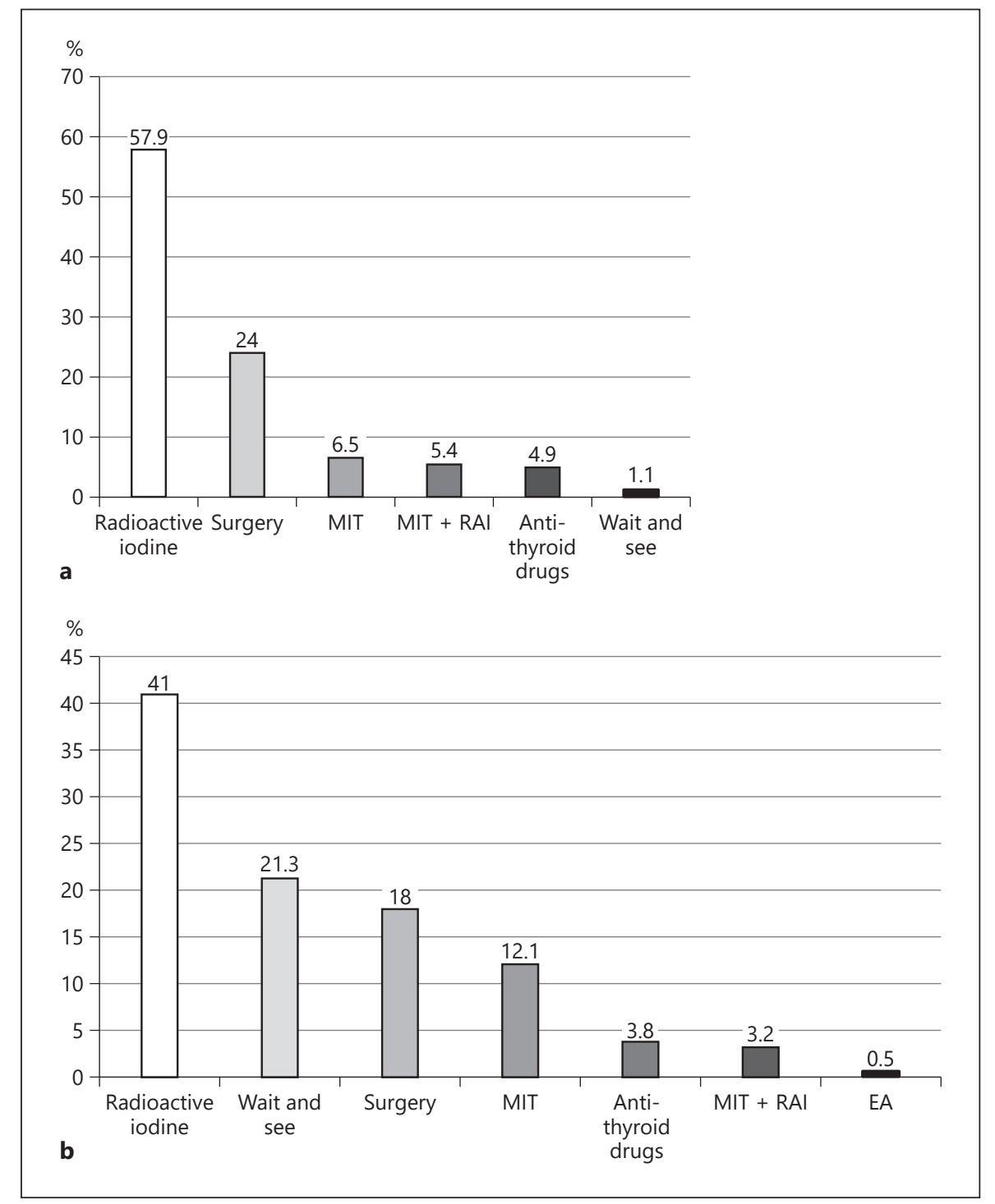

vs. surgery; $p=\mathrm{NS}$; Question 17). Less frequent recommendations were levothyroxine treatment (1.1\%), aspiration of cystic fluid only (15.6\%), liquid drainage followed by TA $(6.5 \%)$. On the other hand, the rate of those who would refer the patient to surgery fell to $4.3 \%$ for elderly patients with cardiac comorbidity, in which case $91.5 \%$ of respondents would offer MIT as primary treatment (MIT vs. surgery; $p<0.01$; Question 18).

\section{Solid Nodule}

For a 25-year-old woman with a $4.0 \mathrm{~cm}$ spongiform nodule (EU TIRADS class II at US) [15], the majority of respondents would offer surgery and only a minority TA (Fig. 2a; $p<0.01$; Question 19). For a nodule with the same characteristics in a 75-year-old patient with cardio- vascular co-morbidity, the relative percentages markedly changed as TA was preferred to surgery $(p<0.01)$. However, about $20 \%$ of the specialists still chose a wait and see strategy (Fig. 2b; Question 20).

For a euthyroid middle-aged woman with a $4.0 \mathrm{~cm}$. thyroid nodule (EU TIRADS class IV at US), $70.7 \%$ of ETA members suggested surgery, and only $20.4 \%$ suggested TA ( $p<0.01$; Question 21).

\section{Hyperfunctioning Nodule}

For a 65-year-old woman with a $4.0 \mathrm{~cm}$ autonomously functioning thyroid nodule (AFTN) causing subclinical hyperthyroidism and compressive symptoms, RAI was suggested by the majority, with surgery as the second, and TA as the third option (Fig. 3a; use of RAI vs. surgery or 
Fig. 4. a Choice of therapy for a 75-yearold female patient who underwent thyroidectomy with lateral and central compartment neck dissection for differentiated cancer and afterwards developed local non radioiodine-avid lymph node metastases (Question 24). b Choice of therapy for a 25-year-old female patient who underwent thyroidectomy with lateral and central compartment neck dissection for differentiated cancer and afterwards developed local lymph node metastases and considered at high surgical risk (Question 25). c Choice of therapy for a 78-year-old female patient harbouring a cytologically confirmed $8 \mathrm{~mm}$ intra-thyroidally located papillary thyroid cancer (Question 26). HIFU, high intensity focused US.
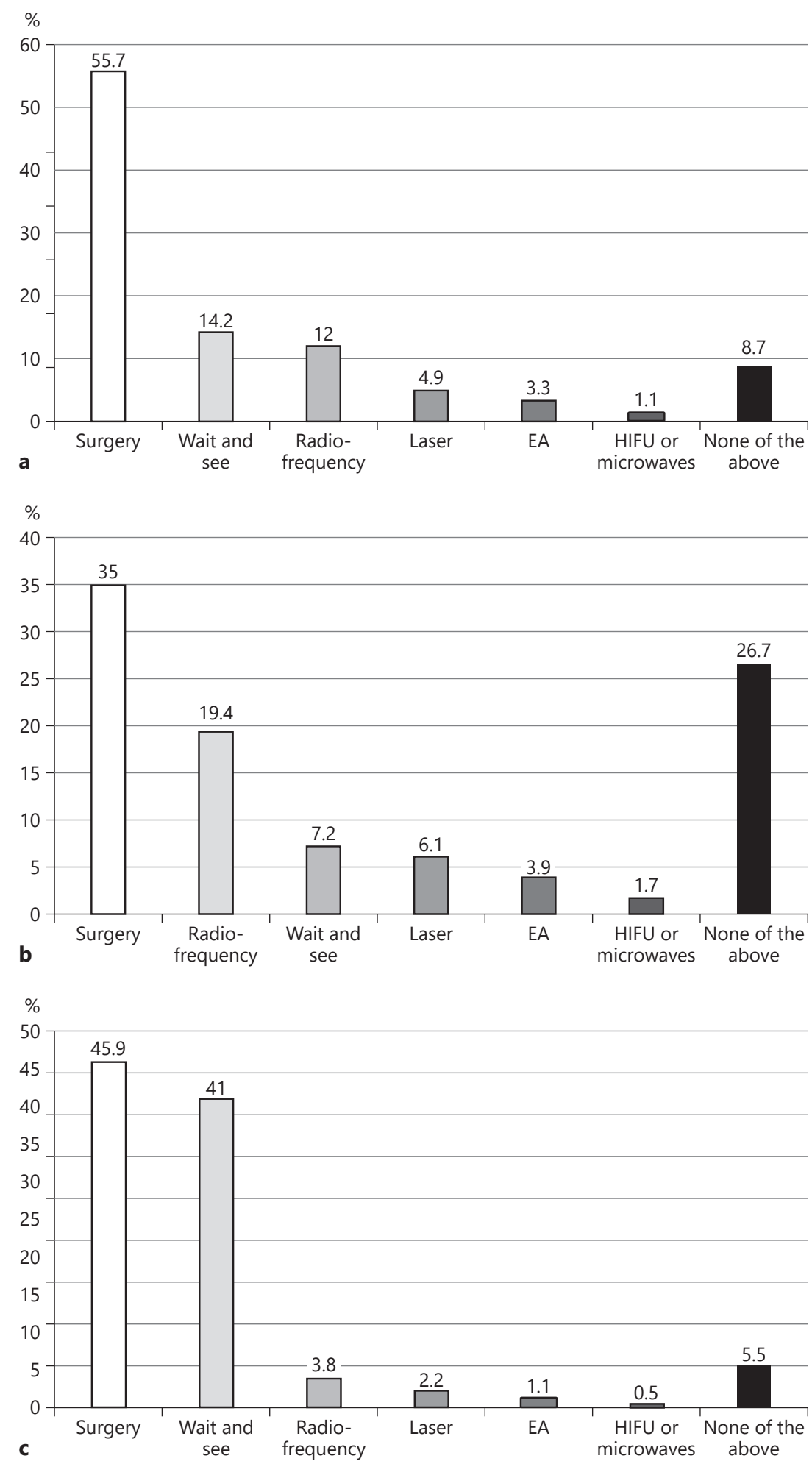
TA; $p<0.01$; Question 22). For a 20-year-old female with a $2.5 \mathrm{~cm}$ AFTN, RAI was again considered the first option, followed by a wait-and-see strategy and, only thereafter, by TA (Fig. 3b; RAI vs. wait and see; $p<0.05$; RAI vs. TA or surgery; $p<0.01$; Question 23).

\section{Thyroid Cancer and Lymph Node Metastases}

For a 75-year-old female patient who had undergone thyroidectomy with lateral and central compartment neck dissection for differentiated thyroid cancer (DTC), and who afterwards developed cervical non radioiodineavid metastases, the majority of respondents (55.7\%) suggested surgery and a minority $(14.2 \%)$ wait-and-see or RFA/LA (16.9\%; Surgery vs. RFA/LA or vs. wait and see; $p<0.01$; Fig. 4a; Question 24). Conversely, if the above patient was a 25 -year-old female, who had undergone thyroidectomy with lateral and central compartment neck dissection for DTC and afterwards developed local lymph node metastases, surgery was recommended by $35 \%$, a wait-and-see approach by $7.2 \%$ (none of the above: $26.7 \%$ ) and TA by $31.1 \%$ of respondents (TA vs. surgery; $p=$ NS; Fig. 4b; Question 25).

Finally, for a 78-year old female harbouring a cytologically confirmed $0.8 \mathrm{~cm}$ intra-thyroidally located papillary thyroid cancer and considered at high surgical risk, thermal therapies represented the third most common recommendation $(7.6 \%)$, after surgery $(45.9 \%)$ and a wait-and-see strategy ( $41 \%$; TA vs. surgery or vs. wait and see; $p<0.01$; Fig. 4c; Question 26).

\section{Discussion}

The widespread use of neck and thyroid US examinations currently result in the diagnosis of nodular thyroid disease in a substantial proportion of the adult population $[4,5]$. About $10 \%$ of such thyroid lesions exhibit progressive growth over time, in general most relevant for nodules already detectable at physical examination [16]. Unfortunately, due to the absence of effective medical treatments $[4,16]$, lesions that cause pressure symptoms or cosmetic concerns, also independent of risk of thyroid malignancy, are generally managed with surgical removal $[17,18]$. This leads to a high frequency of thyroidectomy performed for benign lesions, as demonstrated by recent comprehensive studies in Europe and the United States $[19,20]$. The direct and societal costs of surgery, the low but inevitable risk of complications, and the aesthetic damage induced, represent relevant concerns [21]. Notably, in order to decrease the cosmetic consequences of neck surgery, novel time-consuming and expensive surgical approaches, such as transoral robotic thyroidectomy, requiring specific skills and dedicated tools and carrying risk of further complications, have been proposed [22]. The above considerations, combined with the potential influence on quality of life (QoL), need for thyroid hormone substitution, as well as cosmetic concerns, bring the need of alternative therapeutic options for thyroid lesions that keep growing over time into focus [23].

Various image-guided ablation techniques, with different modes of action, are available for the management of symptomatic benign thyroid nodules [24, 25]. EA for cystic, and TA techniques for solid lesions, have been thoroughly evaluated and considered both safe and effective when used by operators with specific expertise [26]. In the light of the above, and in order to better characterize the diffusion of MIT procedures into current European clinical practice, the ETA conducted a survey among its members. The sample size was thought to be representative, and as previous surveys originated from the responses of approximately $40-50 \%$ of the clinically active members of the ETA [27]. Most important, nearly all the respondents declared a specific expertise in the management of thyroid nodules. This statement was confirmed by the fact that the respondents personally performed thyroid US as well as US-guided FNA. At variance with these data, the use of MIT appears to be limited, with the partial exception of EA, to a minority of thyroid centres in Europe. Moreover, the vast majority of the endocrinologists who did not themselves perform EA, or TA procedures for symptomatic benign thyroid lesions, referred their patients to surgery and did not consider referral to centres with specific expertise in non-surgical TA techniques.

Finally, the interest in using thermal therapies in the management of PTMC or cervical recurrences of DTC was definitely limited. TA was rarely considered an alternative option to a simple wait-and-see approach for elderly persons with PTMC, while the use of TA for neck recurrences of DTC occurring after previous cervical dissection was taken into account only by a minority of respondents.

The present survey showed that physicians familiar with thyroid disease management, and the approach to symptomatic well-defined thyroid phenotypes, only partially embrace the use of MIT, even when supported by robust evidence. Currently available evidence on MIT can be compared to the European survey findings, which is discussed in detail in the following sections. 


\section{Core Needle Biopsy}

US-guided CNB usually provides diagnostic results in cases of thyroid nodules or lymph-node lesions with repeatedly inadequate cytological sampling [18]. In large series of nodules with initially non diagnostic FNA, CNB was proved to offer a significantly higher percentage of diagnostic samples, thus reducing the number of surgical interventions [28]. For anaplastic thyroid tumours, lymphomas and metastatic lymph nodes, CNB may also provide preoperative complementary information for the clinical management [29]. The use of CNB for distinguishing benign nodules from follicular neoplasms, in lesions with indeterminate cytology, is not supported by adequate evidence, although some authors suggest that $\mathrm{CNB}$ has the potential to be the first-line alternative diagnostic tool in nodules initially diagnosed as atypia/follicular lesion of undetermined significance [30,31]. Therefore, it is understandable that, in the present survey, more than half of the ETA members considered CNB to be a complementary diagnostic tool in order to limit diagnostic surgery for nodules with inadequate FNA, and for lesions suspected of being anaplastic or other rare thyroid tumours.

\section{Cystic Lesions}

EA is presently recommended by the major thyroid nodule guidelines as the first-line treatment for benign cystic thyroid nodules $[18,32]$, based on the safety of the technique and the nodule volume decrease after EA, ranging from 50 to over $90 \%$. Volume changes are associated with improvement in pressure symptoms and persist in the long-term $[33,34]$. Diminishingefficacy of EA is primarily related to higher baseline volume, the occurrence of rapid haemorrhagic refilling, or the presence of a relevant solid component [33]. Even if trials with TA of cystic thyroid nodules are limited, LA and RFA achieve a significant reduction also of the solid part of complex thyroid nodules and usually control the regrowth of cysts relapsing after EA [35].

Notably, in conflict with the robust evidence on MIT efficacy and safety, $>1 / 3$ of the ETA respondents indicate surgery as their preferred choice for a young patient with a recurrent benign thyroid cyst. This finding clearly indicates that ETA respondents are insufficiently familiar with MIT (EA in this case), as about $80 \%$ of them do not personally perform EA, and since for about $80 \%$ of respondents EA is unavailable as interventional procedure in their institutions. The lack of personal experience and limited availability of such techniques are probably the main reasons driving physicians to refer patients towards surgery instead of MIT.

Minimally Invasive Therapy of Thyroid Nodules

\section{Solid Nodules}

Both LA and RFA induce clinically significant nodule volume reduction and improvement of both cosmetic concerns and pressure symptoms in the majority of patients. Short- and long-term efficacies of the TA procedures have been demonstrated in several single [36] and multicentre randomized trials $[37,38]$. Results are stable over time, with a $>50 \%$ volume reduction at 36 and 60 months and low rate of long-term re-growth. Long-term results appear more favourable in spongiform and complex than in solid nodules [39]. TA procedures are rapid and well-tolerated, effectively performed in out-patient clinics, major complications are rare, and minor complications are reported only in a minority of patients. Most important, post-treatment thyroid function changes are very uncommon [36-38]. Data from validated thyroid disease specific questionnaires assessing QoL changes are limited but a few prospective studies showed significant improvement after TA [24, 36-38].

The body of evidence on the use of MWA is smaller than that for LA and RFA. However, the published retrospective trials, meta-analyses and multicentre prospective studies demonstrated encouraging results (12-month volume reduction ratio of $75-90 \%)$, although the treated nodules were usually small $(<10 \mathrm{~mL})[13,40,41]$.

Prospective randomized trials using HIFU for thyroid nodule ablation are lacking. Volume decrease after HIFU is reported as $50-70 \%$ in single-centre studies [42]. Due to the need of a careful nodule selection, the cost and the limited experience, HIFU is at present considered mainly for patients who decline or are not suitable for other TA options.

We conclude that the minority of respondents who consider the use of TA for symptomatic thyroid nodules focus more on avoiding the risks of surgical intervention in elderly patients than on preventing the life-long adverse influence of surgery on the QoL in younger patients.

\section{Hyperfunctioning Nodules}

Data from controlled trials with LA $[43,44]$ and RFA $[45,46]$ demonstrated the attainment of euthyroidism in about $50 \%$ of the AFTN patients after 12 months. TA was followed by a $>75 \%$ volume decrease and normalization of thyroid function in the majority of small size (e.g., $\leq 10$ $\mathrm{mL}$ ) hyperfunctioning nodules. In contrast, thyroid function was normalized only in a small fraction of larger lesions [46]. Thus, TA appears appropriate for patients with small AFTN who decline, or are not amenable to RAI therapy or thyroid surgery. HIFU appears as less effective than RAI since thyroid function normalization 
was obtained at 12 -months in $94 \%$ of the RAI-treated versus $53 \%$ of the HIFU-treated subjects [47]. Data concerning the efficacy of MWA is presently considered insufficient.

Notwithstanding the favourable data concerning LA and RFA, the current survey demonstrates therapeutic inertia in dealing with small AFTN in young patients, as $21 \%$ of respondents indicated a wait-and-see strategy instead of TA, a therapeutic option that could control subclinical hyperthyroidism and prevent further nodule growth with low risk of late hypothyroidism.

\section{Thyroid Cancer and Lymph Node Metastases}

TA as well as EA have been reported to offer promising results in the treatment of local recurrent and and/or persistent DTC [48]. The results of the present survey are, to some extent, controversial. While TA was considered an option as valuable as surgery for cervical recurrences of DTC in young patients, it would be adopted only by a small minority of respondents in the elderly.

Despite the growing evidence, even in the absence of randomized controlled trials offering evidence of efficacy of TA for small and low-risk PTMCs [49, 50], the use of TA is currently considered only by a small minority of the responders, and is deemed as a less appropriate management alternative than watchful waiting without any intervention.

The main scope of our survey was to test the attitude of ETA members towards the use of MIT in benign thyroid nodules and cysts. A survey dedicated to the use of MIT for thyroid malignancies, and addressed to clinicians committed in their practice to thyroid oncology, is needed to provide more accurate results on the perceived role of MIT in that specific field.

A strength of this survey is that respondents were from European countries, albeit we acknowledge that about one of four respondents were from outside Europe. The exact number of European ETA-members who clinically manage thyroid patients is unavailable; as a consequence, we cannot generalize our findings to all European thyroidologists. The number of analysed responses is somewhat small to draw firm conclusions and the small number of thyroidologists from each single country made any comparison between countries unreliable. The high proportion of ETA members who did not open the questionnaire, the number of who did not answer all the questions, and the lack of both content and construct validation of the questionnaire are other limitations to the interpretation of the data. In surveys, self-selection of respondents is an unavoidable bias that may distort conclusions from gathered data. However, it most likely that our data represent a best scenario, as for availability of MIT to thyroid patients, in view of the representation of specialized centres and the fact that the vast majority of respondents routinely treated thyroid patients. It is unlikely that a real-world scenario, interrogating an unselected group of physicians, globally seeing the majority of thyroid patients, would have demonstrated a higher implementation of MIT in this patient group.

\section{Overall Conclusions and Perspectives}

Up-to-date management of nodular thyroid disease demands availability of several diagnostic and therapeutic modalities in order to obtain a correct diagnosis and offer appropriate treatment options. The present ETA survey shows that while US, US-guided FNA and surgery are widely available, other well-established techniques such as CNB and EA are performed personally by only about 10 and $20 \%$ of respondents respectively. Importantly, TA procedures are, on average, available to only $16 \%$ of the respondents. A worrying finding, that requires action, is the fact that the overwhelming majority of ETAmembers are unfamiliar with MIT, which is performed, on average, by only about $5 \%$ of respondents. Even less acceptable is the lack of referring patients, whatever their phenotype, to centres with ability to perform these procedures.

Several reasons may explain why therapeutic techniques, some, in this case MIT, available for decades, have not to a higher degree been implemented. Among these, the absence of dedicated training courses and the lack of an appropriate and consistent reimbursement policy by the National Health Services are possibly the most relevant. As a wake-up call to the ETA the most common explanation provided by the respondents was lack of adequate information and the absence of guidelines from the major Endocrine Societies. As a consequence, the ETA has appointed a panel of experts, with dedicated expertise in MIT, in order to provide clear and evidence-based recommendations for the use of MIT. In the near future, the availability of authoritative guidelines, and the establishment of and access to dedicated courses for training, are intended to improve this still unsatisfactory use of nonsurgical procedures for clinically relevant thyroid lesions, and thereby address the current geographic inequality in therapy options. 


\section{Acknowledgement}

There are no acknowledgments to declare.

\section{Statement of Ethics}

Not applicable.

\section{Disclosure Statement}

The authors have nothing to disclose.

\section{Funding Sources}

There are no funding sources to declare.

\section{Author Contributions}

All authors conceived of the presented idea, supervised the findings of this work, discussed the results and contributed to the final manuscript. E.P. and L.H. developed the questionnaire; R.N. evaluated data.

\section{References}

1 Papini E, Pacella CM, Hegedus L. Diagnosis of endocrine disease: thyroid ultrasound (US) and US-assisted procedures: from the shadows into an array of applications. Eur J Endocrinol. 2014 Mar;170(4):R133-46.

2 Melany M, Chen S. Thyroid Cancer: Ultrasound Imaging and Fine-Needle Aspiration Biopsy. Endocrinol Metab Clin North Am. 2017 Sep;46(3):691-711.

3 Papini E, Gugliemi R, Pacella CM. Laser, radiofrequency, and ethanol ablation for the management of thyroid nodules. Curr Opin Endocrinol Diabetes Obes. 2016 Oct;23(5): $400-6$.

4 Hegedüs L. Clinical practice. The thyroid nodule. N Engl J Med. 2004 Oct;351(17): 1764-71.

5 Burman KD, Wartofsky L. Thyroid Nodules. N Engl J Med. 2016 Mar;374(13):1294-5.

6 Ha EJ, Lim HK, Yoon JH, Baek JH, Do KH, Choi M, et al.; Korean Society of Thyroid Radiology (KSThR) and Korean Society of Radiology. Primary Imaging Test and Appropriate Biopsy Methods for Thyroid Nodules: Guidelines by Korean Society of Radiology and $\mathrm{Na}$ tional Evidence-Based Healthcare Collaborating Agency. Korean J Radiol. 2018 Jul-Aug; 19(4):623-31.

7 Kim JH, Baek JH, Lim HK, Ahn HS, Baek SM, Choi YJ, et al.; Guideline Committee for the Korean Society of Thyroid Radiology (KSThR) and Korean Society of Radiology. 2017 Thyroid Radiofrequency Ablation Guideline: Korean Society of Thyroid Radiology. Korean J Radiol. 2018 Jul-Aug;19(4): 632-55.

8 Papini E, Bizzarri G, Bianchini A, Valle D, Misischi I, Guglielmi R, et al. Percutaneous ultrasound-guided laser ablation is effective for treating selected nodal metastases in papillary thyroid cancer. J Clin Endocrinol Metab. 2013 Jan;98(1):E92-7.
9 Zhang M, Luo Y, Zhang Y, Tang J. Efficacy and Safety of Ultrasound-Guided Radiofrequency Ablation for Treating Low-Risk Papillary Thyroid Microcarcinoma: A Prospective Study. Thyroid. 2016 Nov;26(11):1581-7.

10 Persichetti A, Bizzarri G, Guglielmi R, Barnabei A, Bianchini A, Coccaro C, et al. Ultrasound-guided laser ablation for local control of neck recurrences of medullary thyroid cancer. A feasibility study. Int J Hyperthermia. 2018;35(1):480-92.

11 Mauri G, Gennaro N, Lee MK, Baek JH. Laser and radiofrequency ablations for benign and malignant thyroid tumors. Int J Hyperthermia. 2019 Oct;36(2):13-20.

12 Lang BH, Wong CK, Ma EP, Woo YC, Chiu KW. A propensity-matched analysis of clinical outcomes between open thyroid lobectomy and high-intensity focused ultrasound (HIFU) ablation of benign thyroid nodules. Surgery. 2019 Jan;165(1):85-91.

13 Cui T, Jin C, Jiao D, Teng D, Sui G. Safety and efficacy of microwave ablation for benign thyroid nodules and papillary thyroid microcarcinomas: A systematic review and meta-analysis. Eur J Radiol. 2019 Sep;118:58-64.

14 Cibas ES, Ali SZ. The 2017 Bethesda System for Reporting Thyroid Cytopathology. Thyroid. 2017 Nov;27(11):1341-6.

15 Russ G, Bonnema SJ, Erdogan MF, Durante C, Ngu R, Leenhardt L. European Thyroid Association Guidelines for Ultrasound Malignancy Risk Stratification of Thyroid Nodules in Adults: the EU-TIRADS. Eur Thyroid J. 2017 Sep;6(5):225-37.

16 Papini E, Petrucci L, Guglielmi R, Panunzi C, Rinaldi R, Bacci V, et al. Long-term changes in nodular goiter: a 5-year prospective randomized trial of levothyroxine suppressive therapy for benign cold thyroid nodules. J Clin Endocrinol Metab. 1998 Mar;83(3):7803.

17 Bandeira-Echtler E, Bergerhoff K, Richter B. Levothyroxine or minimally invasive therapies for benign thyroid nodules. Cochrane Database Syst Rev. 2014 Jun;(6):CD004098.
18 Gharib H, Papini E, Garber JR, Duick DS, Harrell RM, Hegedüs L, et al.; AACE/ACE/AME Task Force on Thyroid Nodules. AACE/ACE/ AME Task Force on Thyroid Nodules. American Association of Clinical Endocrinologists, American College of Endocrinology, and Associazione Medici Endocrinologi Medical Guidelines for Clinical Practice for the Diagnosis and management of Thyroid Nodules - 2016 Update. Endocr Pract. 2016 May;22(5):622-39.

19 Mathonnet M, Cuerq A, Tresallet C, Thalabard JC, Fery-Lemonnier E, Russ G, et al. What is the care pathway of patients who undergo thyroid surgery in France and its potential pitfalls? A national cohort. BMJ Open. 2017 Apr; 7(4):e013589.

20 Sun GH, DeMonner S, Davis MM. Epidemiological and economic trends in inpatient and outpatient thyroidectomy in the United States, 1996-2006. Thyroid. 2013 Jun;23(6): 727-33.

21 Ben Hamou A, Ghanassia E, Espiard S, Abi Rached H, Jannin A, Correas JM, et al. Safety and efficacy of thermal ablation (radiofrequency and laser): should we treat all types of thyroid nodules? †. Int J Hyperthermia. 2019; 36(1):666-76.

22 You JY, Kim HY, Chai YJ, Kim HK, Anuwong A, Tufano RP, et al. Transoral Robotic Thyroidectomy Versus Conventional Open Thyroidectomy: Comparative Analysis of Surgical Outcomes in Thyroid Malignancies. J Laparoendosc Adv Surg Tech A. 2019 Jun;29(6):796-800.

23 Sorensen JR, Printz T, Iwarsson J, Grøntved ÅM, Døssing H, Hegedüs L, et al. The Impact of Post-thyroidectomy Paresis on Quality of Life in Patients with Nodular Thyroid Disease. Otolaryngol Head Neck Surg. 2019 Oct; 161(4):589-97.

24 Gharib H, Hegedüs L, Pacella CM, Baek JH, Papini E. Clinical review: Nonsurgical, image-guided, minimally invasive therapy for thyroid nodules. J Clin Endocrinol Metab. 2013 Oct;98(10):3949-57. 
25 Papini E, Pacella CM, Misischi I, Guglielmi R, Bizzarri G, Døssing H, et al. The advent of ultrasound-guided ablation techniques in nodular thyroid disease: towards a patient-tailored approach. Best Pract Res Clin Endocrinol Metab. 2014 Aug;28(4):601-18.

26 Papini E, Pacella CM, Solbiati LA, Achille G, Barbaro D, Bernardi S, et al. Minimally-invasive treatments for benign thyroid nodules: a Delphi-based consensus statement from the Italian minimally-invasive treatments of the thyroid (MITT) group. Int J Hyperthermia. 2019;36(1):376-82.

27 Negro R, Hegedüs L, Attanasio R, Papini E, Winther KH. A 2018 European Thyroid Association Survey on the Use of Selenium Supplementation in Graves' Hyperthyroidism and Graves' Orbitopathy. Eur Thyroid J. 2019 Jan;8(1):7-15.

28 Choi SH, Baek JH, Lee JH, Choi YJ, Hong MJ, Song DE, et al. Thyroid nodules with initially non-diagnostic, fine-needle aspiration results: comparison of core-needle biopsy and repeated fine-needle aspiration. Eur Radiol. 2014 Nov;24(11):2819-26.

29 Jung CK, Baek JH. Recent advances in core needle biopsy for thyroid nodules. Endocrinol Metab (Seoul). 2017 Dec;32(4):407-12.

30 Yoon RG, Baek JH, Lee JH, Choi YJ, Hong MJ, Song DE, et al. Diagnosis of thyroid follicular neoplasm: fine-needle aspiration versus coreneedle biopsy. Thyroid. 2014 Nov;24(11): $1612-7$.

31 Na DG, Min HS, Lee H, Won JK, Seo HB, Kim JH. Role of Core Needle Biopsy in the Management of Atypia/Follicular Lesion of Undetermined Significance Thyroid Nodules: Comparison with Repeat Fine-Needle Aspiration in Subcategory Nodules. Eur Thyroid J. 2015 Sep;4(3):189-96.

32 Hahn SY, Shin JH, Na DG, Ha EJ, Ahn HS, Lim HK, et al.; Korean Society of Thyroid Radiology (KSThR); Korean Society of Radiology. Ethanol Ablation of the Thyroid Nodules: 2018 Consensus Statement by the Korean Society of Thyroid Radiology. Korean J Radiol. 2019 Apr;20(4):609-20.

33 Bennedbaek FN, Hegedüs L. Treatment of recurrent thyroid cysts with ethanol: a randomized double-blind controlled trial. J Clin Endocrinol Metab. 2003 Dec;88(12):5773-7.
34 Del Prete S, Caraglia M, Russo D, Vitale G, Giuberti G, Marra M, et al. Percutaneous ethanol injection efficacy in the treatment of large symptomatic thyroid cystic nodules: ten-year follow-up of a large series. Thyroid. 2002 Sep;12(9):815-21.

35 Døssing H, Bennedbæk FN, Hegedüs L. Long-term outcome following laser therapy of benign cystic-solid thyroid nodules. Endocr Connect. 2019 Jul;8(7):846-52.

36 Døssing H, Bennedbaek FN, Hegedüs L. Effect of ultrasound-guided interstitial laser photocoagulation on benign solitary solid cold thyroid nodules - a randomised study. Eur J Endocrinol. 2005 Mar;152(3):341-5.

37 Papini E, Rago T, Gambelunghe G, Valcavi R, Bizzarri G, Vitti P, et al. Long-term efficacy of ultrasound-guided laser ablation for benign solid thyroid nodules. Results of a three-year multicenter prospective randomized trial. J Clin Endocrinol Metab. 2014 Oct;99(10): 3653-9.

38 Deandrea M, Sung JY, Limone P, Mormile A, Garino F, Ragazzoni F, et al. Efficacy and safety of radiofrequency ablation versus observation for nonfunctioning benign thyroid nodules: a randomized controlled international collaborative trial. Thyroid. 2015 Aug;25(8): $890-6$.

39 Negro R, Salem TM, Greco G. Laser ablation is more effective for spongiform than solid thyroid nodules. A 4-year retrospective follow-up study. Int J Hyperthermia. 2016 Nov; 32(7):822-8.

40 Jin H, Fan J, Liao K, He Z, Li W, Cui M. A propensity score matching study between ultrasound-guided percutaneous microwave ablation and conventional thyroidectomy for benign thyroid nodules treatment. Int J Hyperthermia. 2018;35(1):232-8.

41 Cheng Z, Che Y, Yu S, Wang S, Teng D, Xu H, et al. US-guided percutaneous radiofrequency versus microwave ablation for benign thyroid nodules: a prospective multicenter study. Sci Rep. 2017 Aug;7(1):9554.
42 Korkusuz H, Sennert M, Fehre N, Happel C, Grünwald F. Local thyroid tissue ablation by high-intensity focused ultrasound: effects on thyroid function and first human feasibility study with hot and cold thyroid nodules. Int $\mathrm{J}$ Hyperthermia. 2014 Nov;30(7):480-5.

43 Døssing H, Bennedbaek FN, Bonnema SJ, Grupe P, Hegedüs L. Randomized prospective study comparing a single radioiodine dose and a single laser therapy session in autonomously functioning thyroid nodules. Eur J Endocrinol. 2007 Jul;157(1):95-100.

44 Gambelunghe G, Stefanetti E, Colella R, Monacelli M, Avenia N, De Feo P. A single session of laser ablation for toxic thyroid nodules: three-year follow-up results. Int J Hyperthermia. 2018 Aug;34(5):631-5.

45 Sung JY, Baek JH, Jung SL, Kim JH, Kim KS, Lee $\mathrm{D}$, et al. Radiofrequency ablation for autonomously functioning thyroid nodules: a multicenter study. Thyroid. 2015 Jan;25(1): 112-7.

46 Bernardi S, Stacul F, Michelli A, Giudici F, Zuolo G, de Manzini N, et al. 12-month efficacy of a single radiofrequency ablation on autonomously functioning thyroid nodules. Endocrine. 2017 Sep;57(3):402-8.

47 Giovanella L, Piccardo A, Pezzoli C, Bini F, Ricci R, Ruberto T, et al. Comparison of high intensity focused ultrasound and radioiodine for treating toxic thyroid nodules. Clin Endocrinol (Oxf). 2018 Aug;89(2):219-25.

48 Shin JE, Baek JH, Lee JH. Radiofrequency and ethanol ablation for the treatment of recurrent thyroid cancers: current status and challenges. Curr Opin Oncol. 2013 Jan;25(1):149.

49 Valcavi R, Piana S, Bortolan GS, Lai R, Barbieri V, Negro R. Ultrasound-guided percutaneous laser ablation of papillary thyroid microcarcinoma: a feasibility study on three cases with pathological and immunohistochemical evaluation. Thyroid. 2013 Dec; 23(12):1578-82.

50 Zhang M, Tufano RP, Russell JO, Zhang Y, Zhang Y, Qiao Z, et al. Ultrasound-guided radiofrequency ablation versus surgery for low risk papillary thyroid micro-carcinoma: results of over 5 years follow-up. Thyroid. 2020, Epub ahead of print. 